\title{
Emptiness as Potential. Different Conceptions of the Sober Interior
}

\author{
Tim Verhetsel ${ }^{1}$ Fátima Pombo $^{2 *}$, Hilde Heynen ${ }^{3}$
}

\author{
${ }^{1}$ Engineer-Architect, University of Leuven \\ ${ }^{2}$ Guest Professor of Department of Architecture, Urbanism and Planning, University of Leuven, Belgium. \\ E-mail: fatima.teixeirapombo@ asro.kuleuven.be, *corresponding author. \\ ${ }^{3}$ Full Professor and Head of Department of Architecture, Urbanism and Planning, University of Leuven, Belgium
}

doi:10.5618/arch.v2.4 || Received: 2013-01-23, Accepted: 2013-03-03, Available online: 2013-03-09

\begin{abstract}
Emptiness in a contemporary interior design is often sought by architects and designers in order to achieve order, frugality and purity as a counterpoint to the stressful, busy and noisy outside world. A point of reference for this ideal is the Japanese architectural tradition of quietness, sobriety and harmony of mind, spirit and nature. It is our intention with this article, to focus on the meaning of emptiness from a critical perspective clarifying its potential within home interiors. We differentiate between three visions on emptiness, which each offer a different interpretation of the experience of home and its relation to nature, time and beauty: the ascetic emptiness identified with the Japanese tradition and wabi-sabi philosophy, the constructivist emptiness defended by the Russian Constructivism and by philosophers such as Walter Benjamin and the minimalist emptiness as a response to postmodernist aesthetics. We present two case studies, which both can be seen as contemporary variants of sobriety and emptiness: the formal minimalist emptiness of John Pawson's house versus the more organic emptiness of Marie-José Van Hee's house. We conclude by highlighting the difference between the different theoretical frameworks, and their potential bearing upon contemporary interior architecture.
\end{abstract}

Keywords: emptiness, home interiors, interior architecture, Japanese architectural tradition, interpretation

"Room in the Japanese residence becomes human only through man's presence. Without him there is no human trace. Thus, the empty room provides the very space where man's spirit can move freely and where his thoughts can reach the very limit of their potential." (Engel)

"Poverty and experience. This should not be understood to mean that people are yearning for new experience. No, they long to free themselves from experience; they long for a world in which they can make such pure and decided use of their poverty - that it will lead to something respectable.”(Benjamin)

"By repressing everything around us that is not authentic, the architecture of simplicity, minimalist architecture, attempts to draw us to a different way of living, one that is calmer, more serene, more worthy." (Bertoni)

\section{Introduction}

Emptiness in the interior has many faces. Engel, Benjamin and Bertoni each point out different promises related to the idea of a sober interior: quietness and potentiality for Engel, adequacy and respectability for Benjamin, authenticity and serenity for Bertoni. 'Emptiness' thus stands for many things. There is a common understanding in contemporary interior design that emptiness has to do with an absence of ornamentation and decoration, and refers to a condition in which there is no overload of signs and objects that might block the experience of space and spatiality. Nevertheless closer analysis shows that there are many different ways of interpreting 'empty' interiors. This article analyses the genealogies of different understandings of emptiness in the interior, in order to highlight how seemingly similar sober interiors can nevertheless belie quite divergent attitudes. It discusses several theoretical approaches that are crucial for reading 'empty' spaces nowadays, showing through 
some case studies how practices of inhabitation can be expected to be different in each of these approaches.

We start by discussing the Japanese architectural tradition, which opts for emptiness as a possibility offered to the inhabitant for creating imaginary worlds, invoking a natural restoring of mind and spirit. Emptiness in this tradition is the outcome of designing buildings as a unity. Inside, outside and landscape are intertwining in an organic way. Light, shadow, materials, volumes, shapes, frames, floors, corridors are featured to provide a natural, simple, delicate, meditative atmosphere. Next we will pay attention to a specific branch of modernism that heralded emptiness in the interior. This branch is Constructivism, which advocated emptiness as the proper way to accommodate the new classless society by guaranteeing anonymity and flexibility. The theoretical underpinning of this position is best represented in the writings of Walter Benjamin and in the design by Hannes Meyer for the socalled Coop-Zimmer (1929). Lastly we turn towards Minimalism, which, we will argue, too easily associates itself with the sparse Japanese interiors. This most recent tendency embracing sobriety and cleanliness is based upon the search for pure form and visual silence as a reaction to the postmodern condition. We will discuss the John Pawson house as an iconic example of Minimalism, contrasting it with the Marie-José Van Hee house, which we will describe as a more complex and ambivalent realization of the empty interior.

\section{Ascetic Emptiness}

Traditional Japanese architecture developed a very specific vision on emptiness, which materialized in temples as well as in dwellings. It is strongly influenced by the tea cult and Zen Buddhism. Sen-no-Rikyu (151891) perfected this tea cult and with him it became a popular practice among the Japanese population [1]. The idea behind this tea cult is the simplicity of tea pouring. There are a limited set of procedures one can use to pour tea. It was customary to perform these procedures or rituals in a solitary tea hut or tea room. This was a specific building or room dedicated to the drinking of tea. This simplicity also found its roots in the modest and the poor life of the Japanese farmers. The connotation of the austerity of the farmer's house transformed from negative to positive. Poverty could lead to a heightened sense of spirituality, like a hermit who lives in solitude in a forest. This particular form of poverty was labeled wabi by Sen-no-Rikyu. Wabi is a form of voluntary poverty [2]. People have a choice in this sense of poverty. This gives a completely other perspective to life. It is a conscious decision to leave the material world behind and try to live a life dedicated to simplicity and spirituality. The other perspective on life is featured by cherishing the small things in life. It's not about money, success or fame, but about the small daily rituals, acts and views that bring joy to one's existence. $W a b i$ is thus closely related to sabi, which is the aesthetics of the practice of poverty. The small acts and details provide a sense of aesthetics. So in short, wabi can be seen as a philosophical term to describe a voluntary poverty and sabi can be seen as the practical fulfillment of this principle. This complete relation is called wabi-sabi. The entire universe in wabi-sabi can be considered as empty [3]. It exists as either an evolutive state, like in a newborn child, or as a devolutive state, like in an elderly man. In both cases, the universe has the potential to evolve or devolve to a state of emptiness. This potential of emptiness can be translated to an interpretation where not the emptiness as such is important, but rather that what can fill the emptiness. This provides a perspective of emptiness which isn't dominated by a negative connotation, but rather with a positive meaning. Emptiness can create something, it can give space to new thoughts, new creations. In the daily life the first step towards these possibilities, is the creation of emptiness inside one's thoughts. By removing superfluous material objects and a dissociation of the ties between object and subject, only the essential and functional get a place in the mind. Beautiful objects however can be kept to admire and inspire [4].

The poverty in the concept of wabi-sabi reflects on the Japanese architecture. Simplicity and imperfect details make Japanese architecture interesting and beautiful. The gaps between different materials, the concept of $m a$, give a sense of emptiness and negation. The beholder can choose to imagine a seamless material or can imagine something completely different. This imperfectness can also return in the use or the age of the material. Using a wooden chair can create wear and tear, just like the patina of wood in the façade of building can reveal something about the age of the building. These imperfect details add some layers to the architecture and the meaning of the architecture. The architecture ages and lives together with its inhabitants, it forms a bond between them.

This particular conception of Japanese traditional architecture remains a very strong point of reference for contemporary culture, also in Japan. One should not assume, however, that it is still being practiced on an everyday level in Japan. Inge Daniels argues that the traditional Japanese architecture representing the ascetic ideal of wabi sabi and Zen Buddhism can be found in museums, but only sporadically in the existing built environment [5]. According to her, only "a small upper- 


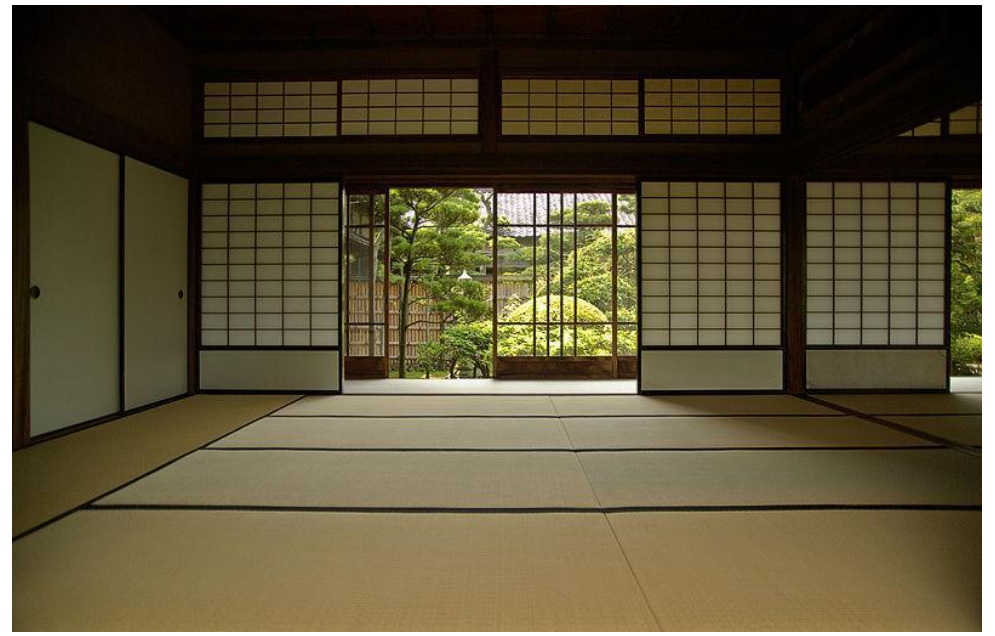

Fig. 1. Traditional Japanese Interior

class elite lived in these kind of dwellings where they practiced the aesthetics of simplicity and social harmony inspired by Zen Buddhism" [6]. The majority of the population in the past didn't have that choice and couldn't afford more than a modest dwelling. In her ethnographic research of the contemporary Japanese home culture, Daniels encounters less austere dwellings and more dwellings with a cluttered, decorated interior, which she sees more as the norm than the exception.

The key idea of emptiness as the feature of Japanese architecture nevertheless is a very popular point of reference in Western and Japanese culture alike, prompted, as Daniels points out, by early publications such as Edward Morse's 1886 book on Japanese Homes and their Surroundings and furthered by the interest of modernist architects such as Frank Lloyd Wright and Bruno Taut. It moreover has some parallels in Western culture too. It can be perceived e.g. in the philosophy of Jean-Paul Sartre, the French existentialist philosopher, who also claimed that negation can trigger imagination [7]. Imagination and nothingness play a substantial role in Sartre's work. For Sartre, imagination is the completion of something hidden or absent [8]. Sartre sees imagination as grasping nothing, as positing nothingness. In "Being and Nothingness" [9] being is linked to nothingness through the act of negation: "Nothingness, which is not, can have only a borrowed existence, and it gets its being from being" [10]. The link between negation, which makes imagination possible, and imagination in itself creates a freedom for the subject to be able to live in this world [11]. Sartre, like traditional Japanese home culture, conceives absence, emptiness and nothingness as crucial conditions for imagination and authenticity.

\section{Constructivist Emptiness}

In the beginning of the twentieth century, Russian Constructivism, rather independently from the Japanese tradition, developed its own sense of interior spaces as basically empty containers where the furniture was purely functional and decoration largely absent. The work of the Russian Constructivists is marked by the social transformation of the worker class. The new socialist state of the Soviet Union tried to transform its workers according to a socialist ideal of collectivity [12]. One way to accomplish this was the use of architecture and art. The work of artists Alexander Rodchenko and Vladimir Tatlin provides concrete examples of the practical interpretation of these socialist ideas and theories, whereas Boris Arvatov was among those who formulated the theoretical basis for these practices [13]. Arvatov tried to break with capitalism and consumerism by replacing the need for possession by a new relationship between person and object [14]. The object should become a companion instead of a slave. Arvatov saw this new relationship in functional and active objects, this includes for example multifunctional furniture, reversible clothing and revolving doors [15]. In a Constructivist interior, this theory was interpreted as an empty volume with the most essential pieces of furniture. These essential pieces were transformable so they could be used for a diversity of functions. These transformations should, according to Arvatov, lead to new experiences for the user [16]. The user could see the room differently according to the function that was needed from the interior. In architecture this would translate as buildings and dwellings made of concrete, steel and glass [17]. The Constructivist architecture was seemingly able to be 
disassembled and assembled on a different place. The architecture should be transient. The potential of emptiness for the Constructivists was the elimination of a possessive relationship to objects. Everything should be equal and this would reflect on the inter subject relationships.

Walter Benjamin, the famous German-Jewish philosopher affiliated with the Frankfurter Schule, built upon these ideas in his own writing. Benjamin visited Russia in the winter of 1926-1927, and was very impressed by the Constructivist re-use of interior spaces [18]. His vision of emptiness in architecture, clearly inspired by this experience, is declaring its potential for a new society. The $19^{\text {th }}$ century petit-bourgeois habit, according to him, can't cope with the challenges of modernity. The petit-bourgeois interiors, which he describes as 'imprinted' by its residents, limit the inhabitants' potential. The inhabitants leave traces of their existence in the velvet cushions of the interior, but these traces are so strong that they act as a kind of case. They contain the inhabitant in such a way that they are not free to change. Such interiors moreover warn off strangers to enter the interior. Only the inhabitants themselves are welcomed by such interiors full of knickknacks, layers of textile and other decorations [19]. For Benjamin the concept of emptiness implies an action of purification, literally in architecture, but also in actions and thoughts of people. The latter purification is, according to Benjamin, strongly related to modernity, since modernity for him is typified by poverty of experience [20]. Benjamin uses the German terms 'Erfahrung', the actual life experience, and 'Erlebnisse', temporary sensations of daily life, to explain this poverty [21]. In modernity, he explains, life experience - 'Erfahrung' - is no longer of paramount importance, since conditions change so fast that one can no longer rely upon old wisdoms. 'Erlebnisse', on the other hand, - fleeting, ephemeral sensations - are multiplying and are increasingly replacing 'Erfahrung'. This process generates a sense of alienation. For Benjamin empty interior can provide an answer to this situation. The petit-bourgeois interiors should make way for empty, pure interiors, where one can't leave any traces of one's existence. It should be a clean slate, where anonymity and flexibility take the place of possessiveness. Benjamin pleads for the destruction of the traditional petit-bourgeois interiors to make room for something new [22]. These empty interiors would reflect the poverty of experiences of the inhabitant, but also would also give them the opportunity to become equal with others. One cannot differentiate oneself from others by one's interior. The emptiness in the interior can be seen as an equal variable in the existence of every human being. This provides the potential to invoke the collective life of the inhabitants. This new collective life can be seen in two ways. In one way the empty interior eliminates every trace of the inhabitants, which could lead to a more welcome feeling towards strangers and others. In this sense, the emptiness provides a collective life inside the interior. On the other hand, the bare interiors could also stimulate a more intense use of the public and collective spaces. Inhabitants of these empty interiors would thus be driven towards each other, in order to share and find a new kind of 'Erfahrung' in the modern world. The empty interiors cancel the individuality of petit-bourgeois habits and create the potential for new life experiences in a world otherwise dominated by temporary sensations. Benjamin recognizes this purification in the text 'Glasarchitekur' by Paul Scheerbart. According to Benjamin glass is the ultimate enemy of possessions [23].

One could point to Hannes Meyer's Coop Zimmer as a significant visualization of this Benjaminian emptiness. Hannes Meyer, a Swiss architect, prominent Constructivist and director of the Bauhaus 1928-1930, is known for his leftist sympathies. For him modern art and architecture were harbingers of the future classless society. His Co-op Zimmer represents a critique against the petit-bourgeois interior. It plays with the notion of a nomadic existence, where transience and instability prevail over permanence and rootedness [24]. The Coop Zimmer is a rather bare space, with minimal furniture - a bed, a side table with gramophone, a folding chair, a bookshelf. Aesthetically it is marked by pure forms (rectangle, square, circle, triangle). This combination of pure forms and commodified, standardized objects give the modern 'semi-nomad' "the benefit of freedom of movement, economies, simplification and relaxation" [25]. Meyer thus demonstrated a new concept of living in this experiment, which remained, as it was only a one-time photograph, an experiment.

Later neo-marxist thinkers of the so-called Venetian School, including Massimo Cacciari and Francesco Dal Co, build upon Benjamin's philosophy and further radicalized it, adding more layers to the meaning of emptiness. Both Cacciari and Dal Co reflect on the possibility of 'dwelling' in the modern condition, referring to the idea of dwelling as conceived Martin Heidegger in his famous essay "Building, Dwelling, Thinking". According to Cacciari modern man can still build, but lost his ability to dwell [26]. So Cacciari uses the concept of emptiness to describe a position or possibility for the modern dweller, in this case the architecture of empty signs [27]. This architecture 


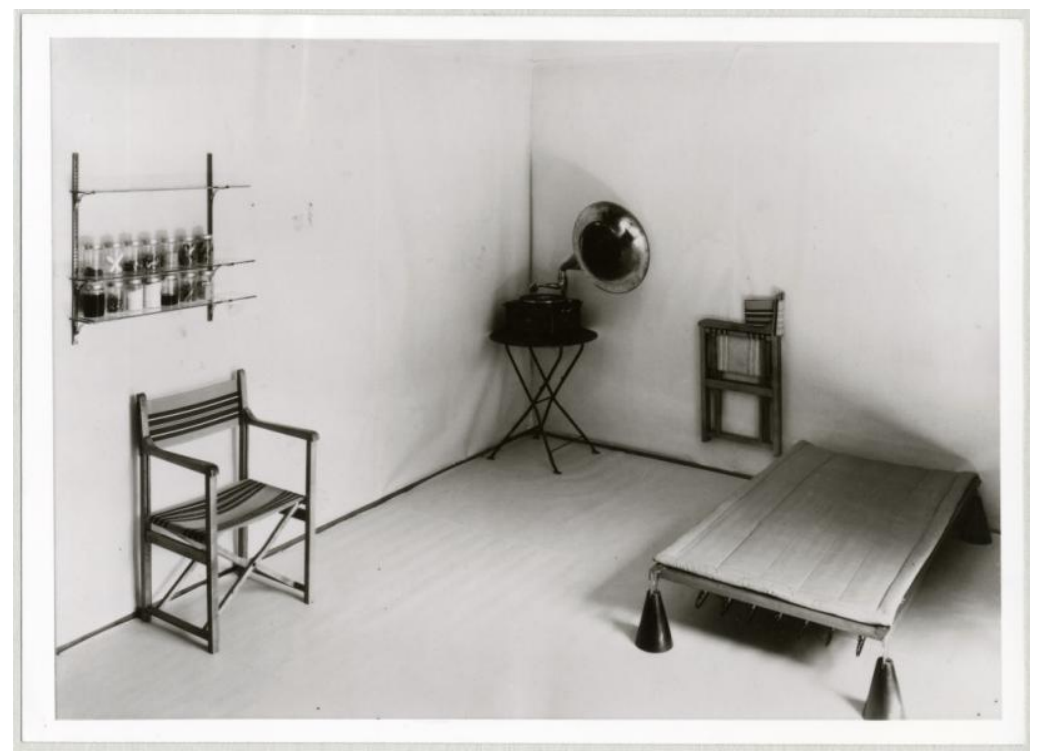

Fig. 2. Co-op Zimmer, Hannes Meyer

confronts the inhabitant with the fact that he doesn't know how to dwell. In a way, this could open possibilities for a new kind of inhabiting. Only when architecture shows its 'sublime uselessness' (the term is from Manfredo Tafuri), without ornaments and other traces of existence, only then can one build truthfully, recognizing that 'dwelling' has become impossible. Cacciari refers to the architectures of Loos and of Mies as clear examples of this emptiness and silence, which state the truth about the impossibility of dwelling. The emptiness confronts the inhabitant with his poverty, and this, according to Dal Co, is destiny: "The appearance of this difference [between modernity and dwelling] is hence the challenge that has to be met, the danger against which the utopia of the modern organizes itself as an extreme resistance, in its desperate attempt to (...) redeem that poverty" [28]. The empty signs in the interior add to an egalitarian environment. The impossibility of dwelling and the coldness of the interior should be countered by the potential and the warmth of the collective spirit.

\section{Minimalist Emptiness}

Minimalist architecture as an architectural style has some loose ties with Minimal Art [29]. Both styles seek to find the purest form and the cleanness of the geometric trace, but with different ambitions and intentions. Minimalist architecture as a term is rather vague, often applied with slightly different meanings in different contexts by various authors and critics. It is mostly used as a label referring to all architecture from the eighties onwards that exalts purity and simplicity, claiming to be influenced by the traditional Japanese architecture. Works dating from before this period, however, might also be categorized as Minimalist, like e.g. the Farnsworth House of Mies van der Rohe (1951) [30]. On the other side, some architects are identified as Minimalist architects, but they don't consider themselves as Minimalist. Indeed the term 'Minimalist architecture' has to be handled with caution, because it might open to ambiguous interpretations [31]. We will follow here Bertoni, who develops the most consistent understanding of the term.

Minimalist architecture starts from the idea that a pure and simple interior space unfolds feelings of inner calmness and peace. Everything that is superfluous should be avoided [32]. The interior often displays a space with white walls, seamless detailed materials and the presence of few objects. Whiteness plays an essential role for the connotation of Minimalist image with pure language and absence of any 'visual pollution'. The seamless materials used for the floor or furniture are chosen to create an uninterrupted effect of coherence. The unbroken view adds to a visual unity, and thus, to a visual silence. The sober presence of objects has the same function as the white walls or the seamless detailing. There is no flexibility in these setups, only in the creativity of the inhabitants. Every form is detailed to its most essential perfection. The aesthetical search for a pure form reflects the belief that life's meaning is in connection with a core of essential elements. Minimalist interiors and the consequent emptiness require a new vision about modern life. Architecture and inhabitant have to find a common 
ground and in this case, that's the inhabitant who has to adapt to his/her surrounding atmosphere. Living in an empty, Minimalist home can be a difficult undertaking, but it has the potential to give useful rewards in the modern world. The emptiness could act as a counter form to the overflow of information that people have to process everyday. The silence of a space can be an important feature in contrast to the hectic life in the (post) modern condition [33]. The Minimalist dwelling becomes a kind of temple for its inhabitants. It locks out the noise of the outside world and provides a space where one can find peace.

Minimalism can thus be seen as a position countering mainstream tendencies in the postmodern world. To keep the essential geometry as pure as possible, the architecture requires some serious dedication from the inhabitants who have the task to keep the dwelling extremely neat and should have the discipline to live in an austere interior. This implies that they can't consume everything they desire. Adding objects in the interior may break the provided visual silence and thus, break the inner harmony. It might be stated that this habit can be commendable as an ecological choice and that Minimalism offers the potential to induce, in a particular way, a more sustainable form of living.

4. 1 Formal Emptiness. John Pawson (1949) is considered the representative of the Minimalist architecture in the mid eighties. Pawson learned architecture by lots of travel to, for example, Japan. This has had a great influence on his architectural work and personal life. He considers himself one who lives Minimal and therefore builds Minimalistic [34]. The Pawson House is a renovation of a traditional Victorian house in West-London. The exterior was held intact, but Pawson tried to renew the façade with some plaster and white paint. Apart from that act, the exterior hasn't been changed. The contrast with the changes in the interior is enormous, once Pawson removed almost everything from the inside. He tried to work with some existing elements, but at the end, his pure vision could only work when he started from scratch, tabula rasa. Then, he started all over with just the front façade as a constraint.

The own built home of an architect is often a billboard for his/her architecture. In this case, Pawson wanted to focus on the dwelling experience, more than on the advertising character [35]. This can be noticed in the floor plans of Pawson House. It's not just an unconventional house but rather an exercise to balance practicality with pure geometry and forms. The entrance is situated on the ground floor, which also incorporates the living room. The living room has a view over the collective gardens in the backyard. Pawson chose to place the kitchen and dining room in the lower ground, which gives entrance to the individual garden. This garden is rather a patio that doesn't reveal much of itself to the neighbors or the public in general.

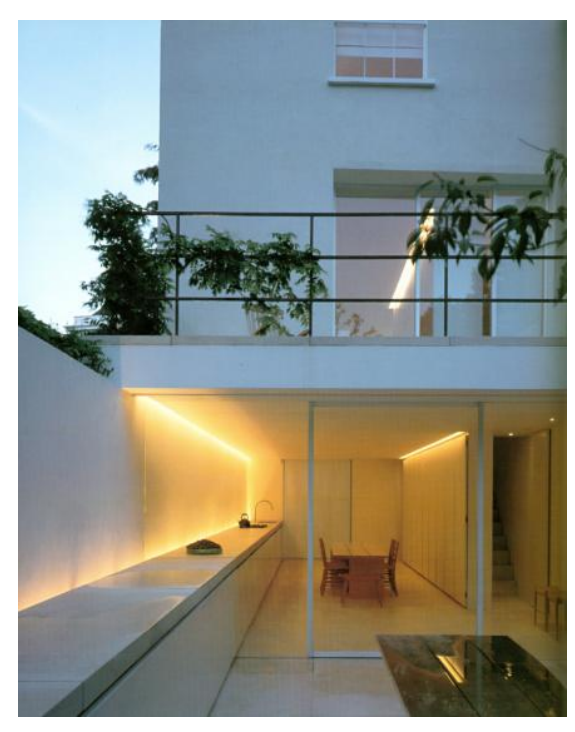

Fig. 3. John Pawson's Home

The two upper floors contain the master bedroom and the two bedrooms for the children. The stairs are designed like a one piece object, without seams. They separate the Pawson house from the neighbor's house over the full length of the house.

In his written and built work, Pawson often reveals an inspiration by traditional Japanese architecture and Zen Buddhism [36]. The Pawson House has some elements of these traditions, but not everything complies in the deepest details. Pawson relates to the introvert character of traditional Japanese dwellings: the windows in the house are more used for light in stead of views to the outside; the patio stands on its own, providing a lot of privacy to the inhabitants. One might wonder, however, whether this introvert character doesn't make this interior the equivalent a contemporary petit-bourgeois one. Minimalism thus walks a fine line while promoting a new lifestyle. The traces of the inhabitants can't be found and their presence is lost amid the pureness of forms and the whiteness of the walls. A Minimalist interior is often not inviting towards others, stressing privacy and seclusion as protection against increasing pressure and hectic character of public life.

The Minimalist interior can provide a safe haven, a place where the inhabitant can regain inner peace by the absence of any distractive element. If Pawson is obviously inspired by Japanese architecture, he also differs from the philosophy behind it. Neither in the 
Pawson House is found the concept of wabi-sabi concerning materials. In wabi-sabi perception, material impurities reveal transformation and an extra experience of time. According to Pawson, every material has to be seamless to achieve the deepest impression of visual silence [37].

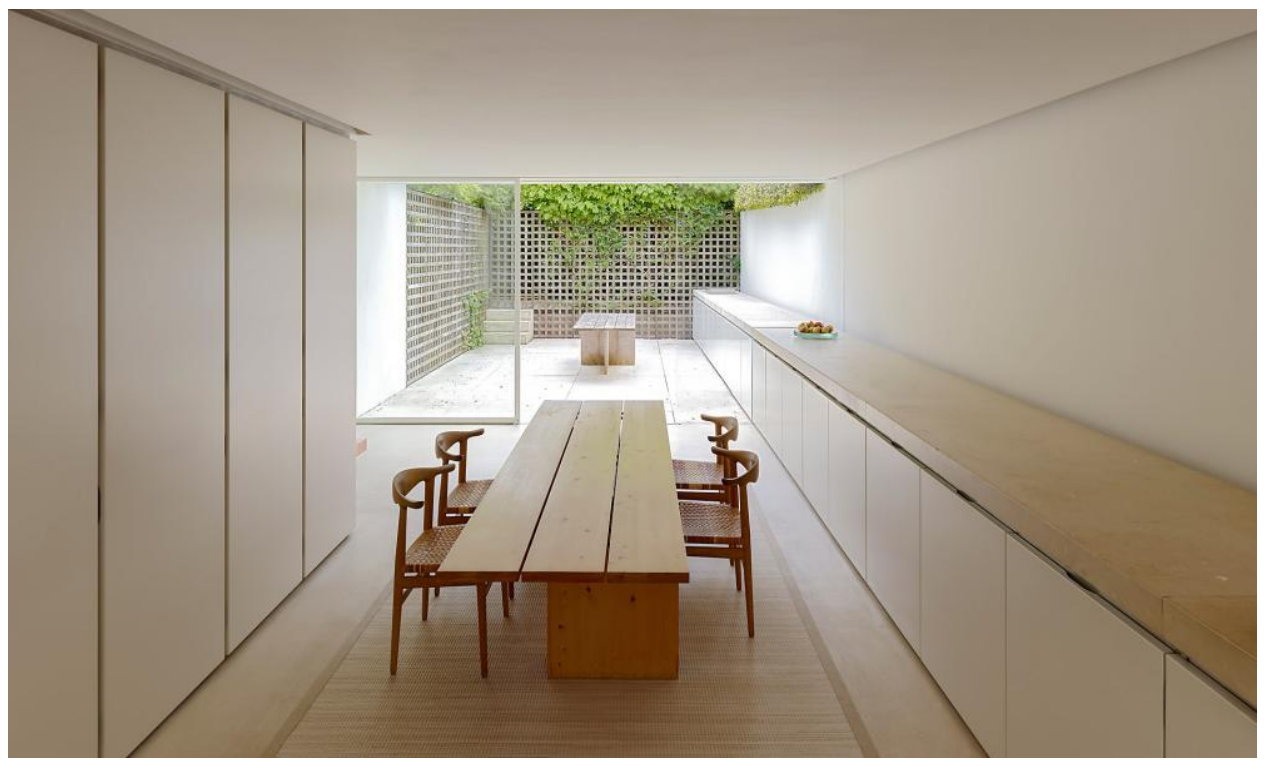

Fig. 4. John Pawson's Home

Emptiness, however, is a key element in the Pawson House, even though we would qualify it as an emptiness of elimination rather than one of possibilities. The architect holds the belief that he already lives minimal, so he can only build minimal. In that sense the Pawson house is to be considered authentic, since the architect designed it as a materialization of his ideology. There is a fine line however between the authenticity of the gesture of translating a Minimalist life-style into a Minimalist interior, and the act of creating a successful brand where Minimalism functions as just a trademark signaling a commercial product. Even more than Pawson himself could have foreseen, this Minimalist style was picked up by many architects, who converted it into a kind of recipe. The real introvert character of the interior is neglected by the superficial copy. This, in fact, also short circuits the real quality of the Minimalist home. It hasn't the sufficient means to withstand its own success. The inhabitants live inside a fixed, ultradesigned decor that almost can't be transformed, otherwise the whole meaning of the copied Minimalism is lost. Emptiness can't be considered as a form of freedom in this kind of Minimalism; it's a strict constraint that limits every move or thought neglecting the relationship between inhabitant and object as, for example, the only place for storage are the large wall units. The bond between object and subject doesn't grow organically over time and with specific memories attached. When the subjective relation between individual and object is not stimulated it might have its positive effects, like for example a lower consumerism. On the other hand, people are restricted by the design of their own home. Adolf Loos described this in his essay "The poor little rich man" [38] and if in a different context, that can still be applied on contemporary architecture. Loos described a rich man who wanted to live in art and asked an architect to build this for him. The architect performed as well as he could and the rich man was happy. But after some time, the rich man became sad because he could not buy new art once this would interfere with the interior designed by the architect. Everything is so geometrically pure that there is no room for the natural dynamic of the inhabitants' life. In this way, emptiness with all its potentiality becomes a dangerous concept.

Minimalist architecture, in contrast to the interpretation of emptiness by Walter Benjamin and the Venetian School, doesn't reinforce the call for a new collective spirit, but rather plays on a need for more individuality. The Minimalist interior isn't an interior of traces, but has the same dangers as a petit-bourgeois interior. Both give the interior such a specific personal and individual character that others don't feel welcome when being there. The popularity of the Minimalist architecture also adds to this critical notion. With the popularization of Minimalist architecture comes a different vision, a vision of transience and fashion [39]. This is in strong contrast to the vision of emptiness that 
brings inner peace and a more down to earth lifestyle. Because of the immense popularity of Minimalist architecture in magazines and newspapers, a particular section of fashionable people is keen to live in a Minimalist house. But the discipline required by maintaining the perfection of the smooth and clean lines of the interior, is at odds with many people's everyday living practices [40]. Domesticity for many has to do with messiness, chaos and clutter, and this cannot easily be accommodated in the pristine interiors of Minimalism. Hence once can question whether Minimalism can indeed become more than a fashionable trend and image in the long run will not be able to adequately integrate real lives of real people. As a last case study, we will therefore turn to another recent house, designed and inhabited by Marie-José Van Hee, which takes up the challenge of emptiness and sobriety but in a way which is quite different from Pawson's Minimalism, and potentially closer, we would argue, to the adaptation of the spirit of Japanese emptiness into an organic emptiness.

4. 2 Organic Emptiness. Marie-José Van Hee (1950) is a Belgian architect, who studied at the Higher Institute for architecture of Saint-Luc in Gent. She graduated in 1974 and started her own architecture office soon after. One of her more well-known designs is the Belgian pavilion at 'la Biënnale di Venezia' in 1991.

Marie-José Van Hee bought four small houses in the center of Gent. She combined the four lots to one, big enough to build a spacious home in the city center. The Van Hee house is designed as an L shape that surrounds an inner courtyard.
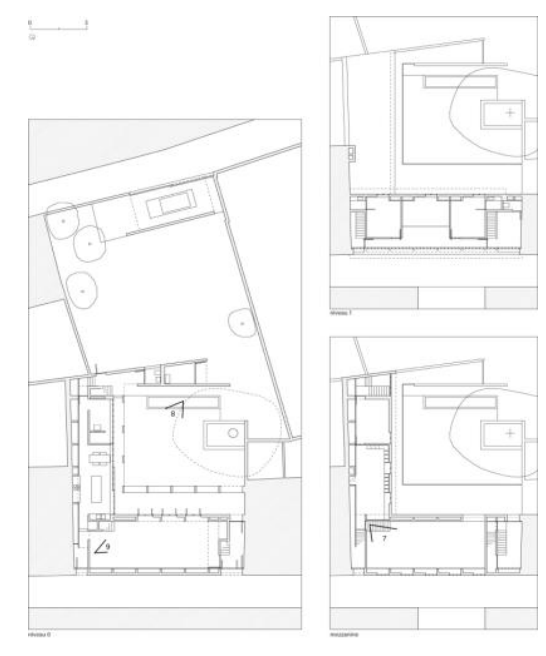

Fig. 5. Plans of Marie-José Van Hee's home

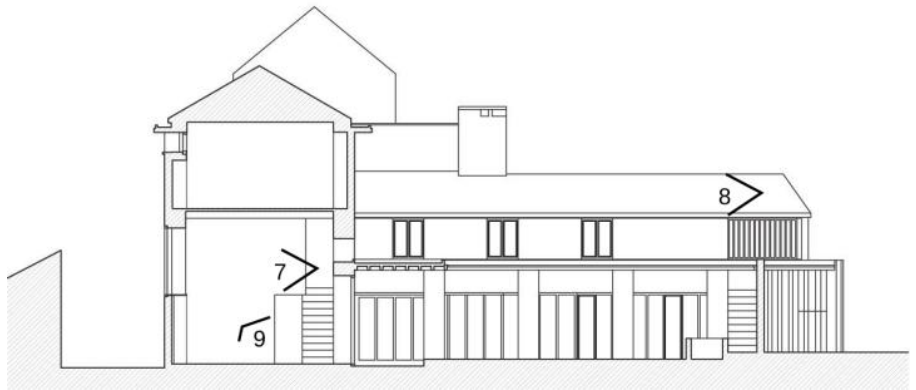

Fig. 6. Longitudinal Section of Marie-José Van Hee's Home
On entering the house, you really tumble inside. There is no real gradient of privacy, the door is the only hard boundary between the public street and the private home [41]. The entrance is situated in the corner of the L-shape, which offers the visitor the possibility to explore whichever side of the house. Parallel to the street is the living room, marked by the double height ceiling and the very thick wall on the street side offering a lot of storage space.

The large windows above these wall units provide light for the living room, but exclude curious eyes from the public. At night these windows bring light to the street, it can be seen as a sort of lantern in the darkness of the night [42]. These windows and their niches accentuate the thickness and vastness of the wall. At the same time, they bring some rhythm to the architectonic design. Another rhythm is found in the ceiling, which reminds the ceilings in the hall of a castle. The living room exalts a kind of austerity and at the same time a dynamic character. Three doors guide the visitor from the living room to the inner courtyard, which is surrounded by an open gallery that reminds one of a cloister [43]. It offers an open circulation in a natural environment. The inner courtyard could be seen as the center of the house [44], a kind of negative volume providing a truly magnificent green heart in the center of Gent. 


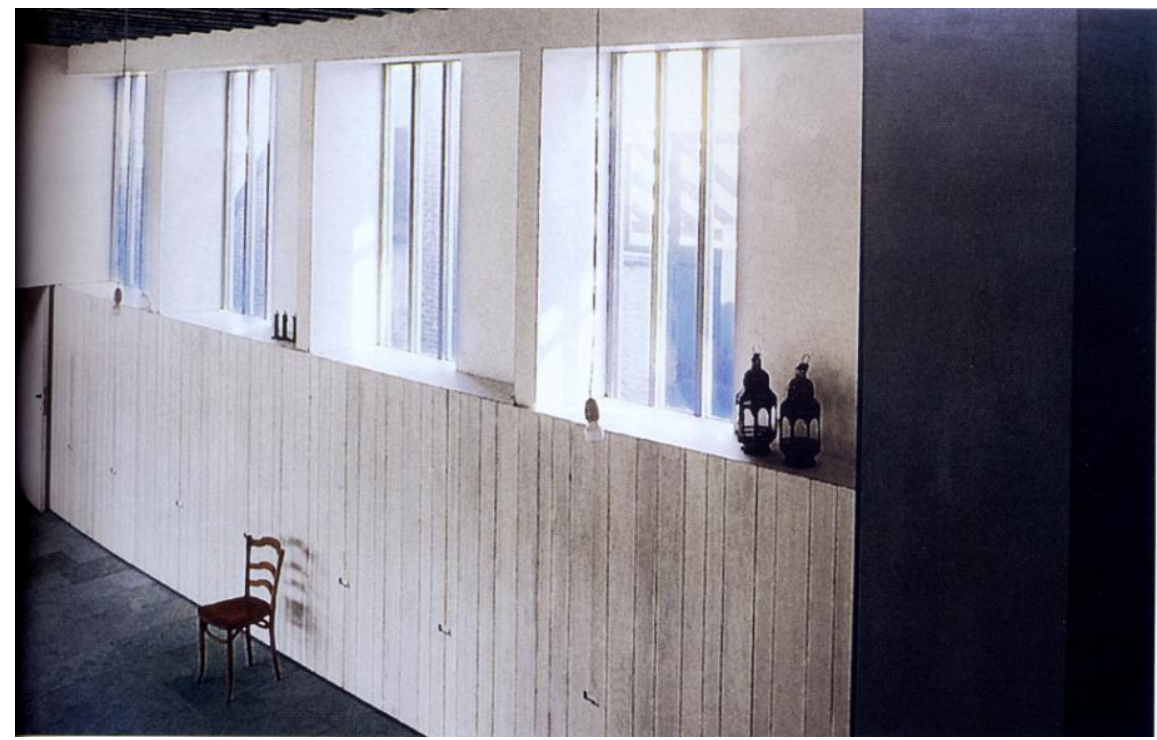

Fig. 7. Storage Space

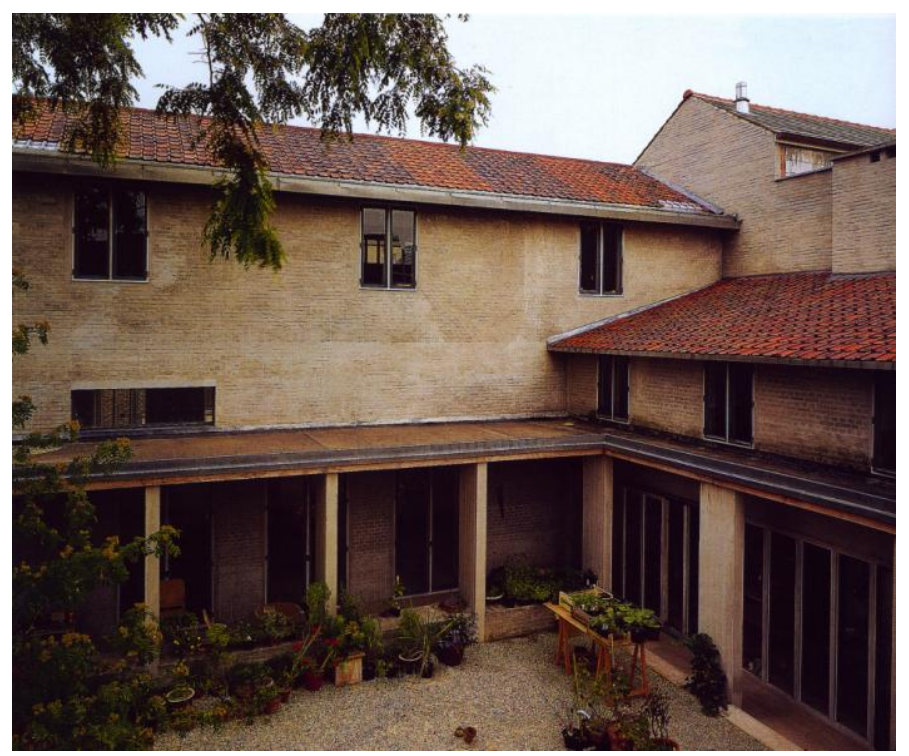

Fig. 8. View of the Courtyard

The other side of the L shape perpendicular to the street provides space for the kitchen and the dining room. The wall separating the Van Hee house from the neighbors is straightened by a large wall unit, which offers a lot of storage space in the different rooms. Behind the kitchen, there is space for a bathroom. Van Hee designed a mezzanine on top of the kitchen, which is accessible with stairs from the living room. The stairs on the other end of the mezzanine connects the kitchen and the mezzanine. The third stairs in the design connects the level above the living room.

Van Hee designed these three stairs to offer a free circulation throughout the house. The different points, where the stairs are located, don't oblige one to always follow the same path and therefore spontaneity is stimulated while at home. Added to this fact is the decision of Van Hee to place the stairs as far as possible from the courtyard. This allows a choice to circulate via the open gallery or not [45]. The house is stretched 
between the three stairs and the inner courtyard, which offers great possibilities in circulation and living experience. The house's design also allows exploring different views of Ghent's skyline or of the garden.
As appears from the description of the Van Hee house, the architect tries to find a balance between contemporary architecture, archetypes and her own vision on dwelling.

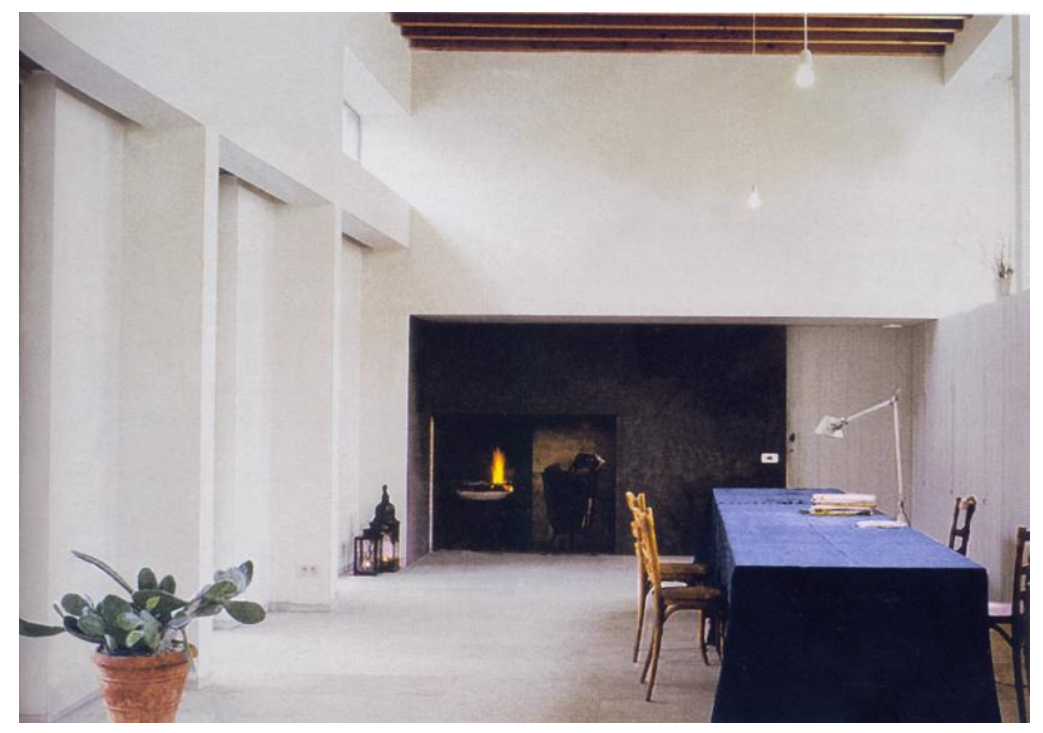

Fig. 9. View on the living room

The archetypes used in this case are the hall and the open gallery with the courtyard. She transforms those archetypes to an adequate scale to dwell, but still recognizable for the connoisseur [46]. She plays with references that create a dynamic whole with the dwelling function. Daily life inside the Van Hee house is not limited by the archetypes. It adds a layer to the place's architectural story remaining functional as well. It's not a decoration as such, but an ingenious design to create new spaces, experiences and freedom inside the house. The Van Hee house can't be labeled in any way. It's a diverse house that can reinvent itself. Every need of the inhabitant is virtually covered, because spaces can provide most functions and typologies under one roof. The house can become a place for contemplation and a place for joyous festivities.

The emptiness in the Van Hee house displays a more natural and organically grown emptiness than the emptiness in the Pawson house. Van Hee wasn't searching for a Minimalist look or a fashion trend, but for a sustainable, sober interior that can withstand time and offering timeless dynamics [47]. With a handful of simple and truthful materials, Van Hee chose modest and discrete materiality for her design creating a more symbolical than literal emptiness.

\section{Conclusion: Emptiness as Potential}

In this article emptiness has been considered on different levels and from different perspectives. The interior of a dwelling can play an important role in the lives of the inhabitants. Considering the concept of emptiness in these different meanings, gives other possibilities to reading or viewing 'empty architecture'. The three different meanings of emptiness we discussed relate to each other, but nevertheless belie very different viewpoints regarding the relation between individual and collectivity, as well as regarding the concepts of nature, time and beauty.

The Japanese, ascetic vision of emptiness focuses on the individual who is stimulated by the emptiness of the interior to develop his spirituality. The simple and sober lines of this architecture stress the bond with nature and allow for a heightened awareness of the passing of time, since changing conditions of light intensely register and mark the experience of the space. Abundance of possessions is not encouraged by these interiors, but cherished objects that contain memories are allowed to be part of it. These interiors thus realize a harmonious form of beauty, expressed in simplicity, geometry and purity, and characterized by a sense of wholeness and unity with nature. 
The Constructivist interiors, on the other hand, do not stress the experience of the individual, but rather depart from an accent on collectivity. They result from a striving towards a classless society, which means that interiors should be shared among many and hence should be accommodating multiple uses. Time in this case is not conceived of in terms of individual experience and memories, but rather as a condition of change, fleetingness, flexibility and transformation. Hence the beauty of these interiors is not one of harmony and unity, but of contradictions, oppositions, paradoxes. Things are not harmoniously interconnected, but point towards multiplicity, diversity and possibly conflict.

Minimalism in architecture as we know it nowadays positions itself in reference to the Japanese empty interiors, and ignores the Constructivist legacy. It focuses again on the individual, and stresses freedom and peace as major features of this way of life. The conceptions of nature, time and beauty that one finds in this approach are therefore very different from the Constructivist ones: nature stands for stability, unity and wholeness (not for environmental crisis), time is seen as motionless (the pristine character of the interior is supposed to not be affected by the passing of time) and the beauty that is strived for is one of harmony rather than disruption.

Our two case studies show how contemporary architects work with these notions. John Pawson of course personifies minimalist architecture and his house is a sublime example of the exalted beauty of emptiness as providing purity, sobriety and peace. The lines of his interior are flawless. At the same time they do not allow for disruption. In order to keep the beauty of this interior, the inhabitants need to be disciplined and to respect the requirements of order and cleanliness. If they don't, the beauty of this interior is no longer convincing. Marie-José Van Hee's emptiness, on the other hand, is of a very different character. In her case, the empty interior works as a framework for everyday life, where domesticity can happen without disrupting the essential qualities of the spaces. Her interior invites a dialectics between emptiness and domesticity, and can accommodate contradictions of use and paradoxes of meaning. One can wonder whether the two forms of emptiness realized in these interiors could also be characterized in terms of gender: a masculine form of order and control on the one hand, based upon the need for discipline in order to free up the potential of spirituality versus a feminine form of accommodation and caring, where the potential that is set free is rather one of intense relationships among people and among people and spaces, or people and objects. It seems that two very different patterns of inhabitation are indeed given form in these houses - although they both realize emptiness as a major factor contributing to the promise of a balanced interior.

\section{References}

[1] H. Engel, The Japanese House: A tradition for contemporary architecture. Rutland, United Kingdom: Charles e Turtle Company, 1980, 280-281

[2] L. Koren, Wabi-Sabi: for Artists, Designers, Poets \& Philosophers. California, Los Angeles: Imperfect Publishing, 2008, 22

[3] L. Koren, 2008, 42

[4] L. Koren, 2008, 72

[5] I. M. Daniels, The 'Untidy' Japanese House. In D. Miller (Ed.). Home Possessions: Material Culture behind Closed Doors, London, England: Berg, 2001, 201

[6] I. M. Daniels, 2001, 207

[7] S. Herrington, S. You Are Not Here: Sartre's Phenomenological Ontology and the Architecture of Absence. Footprint, 3, 2008, 51-64

[8] J-P. Sartre, The Imaginary: A phenomenological psychology of imagination (Original work published in 1940, J. Weber, Trans.). London, England: Routledge, 2004

[9] J-P. Sartre, Being and Nothingness (Original work published in 1953, H.E. Barnes, Trans.), New York, NY: Philosophical Library, 1958

[10] J-P. Sartre, 1958, 16

[11] J-P. Sartre, 2004, 216-217

[12] V. Buchli, An archeology of socialism. Oxford, England: Berg, 2000, 24

[13] C. Kiaer, Imagine No Possessions. Cambridge, Massachusetts: MIT Press, 2005

[14] B. Arvatov, C. Kiaer, Everyday Life and the Culture of Things. October, 81, 2003, 121

[15] B. Arvatov, C. Kiaer, 2003, 126

[16] C. Kiaer, Boris Arvatov's Socialist Objects, October, 81, 1997, 113

[17] B. Arvatov, C. Kiaer, 2003, 126

[18] H. Heynen, Architecture and Modernity: A critique. Cambridge, Massachusetts: MIT Press, 1999, 115; M. Dmitrieva, "Happiness through Discipline. Soviet Cities in the Travelogues of Foreign Visitors in the Nineteen-twenties and Nineteen-thirties". In A. Artetzky \& M. Schallenberg (Eds.), Urban Planning 
and the Pursuit of Happiness. Leipzig: Jovis, 2009, 80-97

[19] W. Benjamin, "Paris, Capital of the Nineteenth Century" [Original work prublished in 1935]. In W. Benjamin, Reflections. Essays, Aphorisms, Autobiographical Writings. New York: Schocken, 1978

[20] W. Benjamin, Experience and Poverty (Original work published in 1933, R. Livingstone, Trans.). In W. Bejamin. Selected Writings Volume 2, 19271934, Harvard, MA: Harvard University Press, 1999, 732

[21] H. Heynen, 1999, 98-99

[22] W. Benjamin, 1999, 734

[23] W. Benjamin, 1999, 734

[24] H. Heynen, 1999, 113

[25] M. K. Hays, Modernism and the Posthumanist subject: the architecture of Hannes Meyer and Ludwig Hilberseimer. Cambridge, MA: MIT Press, 1995, 65

[26] M.Cacciari, M., Eupalinos or Architecture (Original work published in 1980, S. Sartarelli, Trans.), in M. K. Hays (Ed.), Architecture Theory since 1968. Cambridge, MA: MIT Press, 1998, 398

[27] M. Cacciari, 1998, 396

[28] F. Dal Co, Figures of Architecture and Thought. New York: Rizzoli, 1990, 41-42

[29] F. Bertoni, Minimalist Architecture. Basel, Switzerland: Birkhäuser, 2002, 6

[30] A. Ruby et al. (2003). Minimal Architecture, Munich, Germany: Prestel, 2003, 16

[31] A. Ruby et al., 2003, 16

[32] F. Bertoni, 2002, 10

[33] F. Bertoni, 2002, 11
[34] Plainspacelondon, John Pawson - Home [Video file].

Retrieved on 27 December 2012 from http://www.youtube.com/watch?v=lPcG7Q3oG08

[35] D. Sudjic, John Pawson: Works. London, England: Phaidon Press, 2005, 206

[36] D. Sudjic, 2005, 21

[37] J. Pawson, Minimum. London, England: Phaidon Press, 1998, 19

[38] A. Loos, The poor little rich man (Original work published in 1900, A. Sarnitz, Trans.). In A. Sarnitz (Ed.). Adolf Loos, 1870-1933: Architect, Cultural Critic, Dandy, Cologne, Germany: Taschen, 2003, $18-21$

[39] F. Bertoni, 2002, 55

[40] D. Miller, (Ed.) Home Possessions. Material Culture Behind Closed Doors, Oxford: Berg, 2001; H. Heynen, "Modernity and Domesticity. Tensions and contradictions." In: Heynen H., Baydar G. (Eds.), Negotiating Domesticity; Spatial Productions of Gender in Modern Architecture. London: Routledge, 2005, 1-29

[41] A. Loeckx, Marie-José Van Hee's domestic architecture. In H. Heynen, G. Baydar (Ed.). Negociating Domesticity: Spatial productions of gender in modern architecture, London, England: Routledge, 2005, 273

[42] A. Loeckx, 2005, 273

[43] A. Loeckx, 2005, 274

[44] A. Loeckx, 2005, 274-275

[45] A. Loeckx, 2005, 277

[46] A. Loeckx, 2005, 274

[47] A. Loeckx, 2005, 274 